\title{
Climate resilience in the United Kingdom wine production sector: CREWS-UK
}

\author{
A. Nesbitt ${ }^{1}$, S. Dorling ${ }^{2}$, and R. Jones ${ }^{2}$ \\ ${ }^{1}$ Vinescapes, Climate and Viticulture Research Department, Dorking, Surrey RH5 6QW, UK \\ ${ }^{2}$ University of East Anglia, School of Environmental Sciences. Norwich Research Park, Norwich, Norfolk NR4 7TJ, UK
}

\begin{abstract}
As cool climate viticulture rapidly expands, the England and Wales wine sector is winning international acclaim, particularly for its sparkling wines, and is attracting significant investment. Supported by warming climate trends during the growing season, wine producers are establishing new vineyards planted predominantly with Pinot Noir and Chardonnay. Grape-friendly weather conditions in 2018 led to a record harvest and may be a sign of good things to come. Long term (100-years) Growing Season Average Temperatures (GSTs) in south-east and south-central England have noticeably increased with 6 of the top 10 warmest growing seasons (April-October), over the last 100 years, occurring since 2005. However, weather and growing season conditions fluctuate markedly from year to year, meaning that yields and grape quality continue to vary significantly. Weather extremes are anticipated to become more frequent under future climate change, further threatening the stability of production. Current uncertainty over future climatic conditions during the growing season and their potential effects on viticulture in the UK exposes both existing producers and potential investors to unquantified risks and opportunities. The CREWS-UK climate resilience research project is generating actionable information on how climate change may affect the wine production sector, to support better decision-making and investment.
\end{abstract}

\section{Introduction}

Viticulture is the fastest growing agriculture sector in the UK. Vineyard hectarage (ha) in England and Wales increased 250\% (722-2500 ha) between 2004 (when sparkling wine started to dominate production) and 2017. Enhanced investor confidence, sector expansion, widening varietal suitability, and greater viticulture opportunity have been underpinned by climate change, evidenced through recent warming of growing season (AprilOctober) average temperatures. Nesbitt et al. (2018) highlighted the substantial additional opportunities which exist to develop prime UK viticultural land on a scale comparable in size to the Champagne region of France.

However, intra- and inter-annual weather variations significantly affect viticultural productivity. During the 2004-2013 period, UK-wide wine yield varied considerably (6-34 hectolitres per hectare (hL/ha)), averaging just $20.7 \mathrm{hL} / \mathrm{ha}$. Investments in English and Welsh viticulture therefore remain exposed to low and highly variable yields. This exposure is partly shaped by sub-optimal choice of vineyard location and low resilience to observed climatic variability at the cooler end of viticulture, including ongoing vulnerability to air frosts during the critical bud burst period. Even under future projections of a warming climate, frost risk and vineyard site choice remain critical issues, as phenological responses move the 'at risk' period to earlier in the year. Climate change impacts, risks and opportunities must therefore be considered in detail in order to extract knowledge and value from which the UK wine production sector can benefit.

\section{Methods}

The CREWS-UK project is integrating very highresolution gridded datasets of current climate and newly published UK climate change projections (UKCP18, to 2050) with an innovative value chain approach to understanding adaptive behaviour in the UK wine production sector. The project outputs will boost climate resilience, economic growth and sector wide sustainability.

\section{Results}

We will present our early project results on how critical growing season characteristics (Figs. 1 and 2) have changed and how they are projected to potentially change over the coming decades. While it is anticipated that the climate will on average continue to warm, parallel phenological responses (e.g. earlier budburst) and natural climate variability will mean that risks remain at critical points during the growing season. Uncertainty will be quantified through consideration of projections based on multiple models and emission scenarios, consistent with UKCP approaches. We will discuss the implications for changing varietal suitability.

We will present how our research is also examining the dynamics of decision-making (through a series of surveys and interviews with different actors across the value chain). We focus upon the development and application of adaptation strategies across the UK wine production sector, to assess pathways to support economic sustainability and thereby to help to ensure that this fledgling industry has a bright future. Innovatively for impact studies of this nature, 


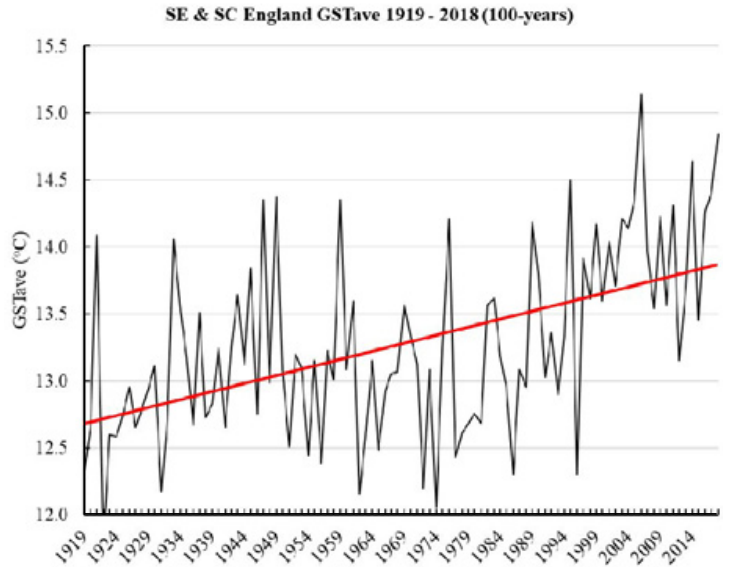

Figure 1. Growing Season Temperature (GST) 1919-2018 in south-east (SE) and south-central (SC) England.

we take a full value chain approach to understanding how each stage and actor, from production to consumption, may be affected by and respond to climate (and other) stresses and opportunities.

Early results indicate that by 2050 , under both low and high emission scenarios, the chance of summer temperatures exceeding those seen in the record harvest year of 2018 will be of the order of $50 \%$.

\section{Conclusions}

The overall direction of change in climate has been positive for UK wine production - therefore we focus, unusually, on both opportunities and risks of climate change. Our climatological work fills an important gap in the sector's ability to risk assess, even in the current climate, and supports consideration of mitigation measures to reduce

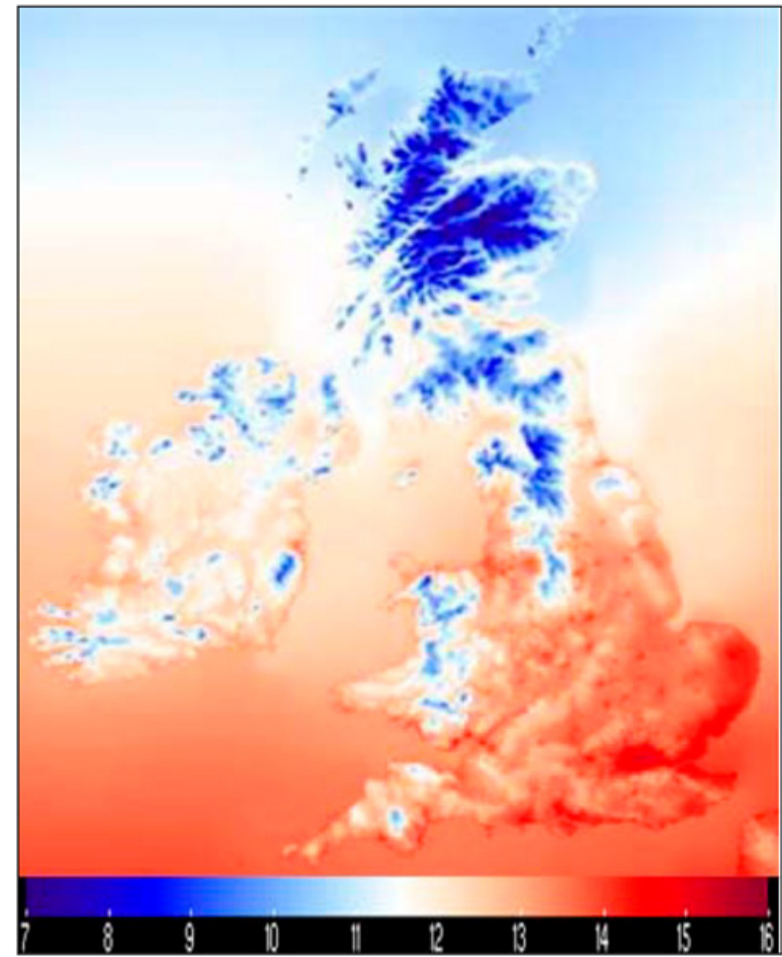

Figure 2. 10-year (2008-2017) mean GST across the British Isles.

vulnerability, including both micro-climate modification techniques and insurance options.

\section{References}

[1] A. Nesbitt, B. Kemp, C. Steele, A. Lovett, S. Dorling, AJGWR 22, 324 (2016)

[2] A. Nesbitt, S. Dorling, A. Lovett, JLUS 13, 414 (2018) 